\title{
Effect of Vitamin D-Fortified Egg on Bone Metabolism in Ovariectomized Osteoporotic Rats
}

\author{
Takayuki KawazoE, Yukihiko IwaI, Jun Yamagoshi, Kaoru NoGUCHI and Katsumi YUASA \\ Kikkoman Corporation, 399 Noda, Noda, Chiba 278, Japan
}

Received October 29, 1996

\begin{abstract}
Ovariectomized osteoporotic rats were divided into four groups: ordinary egg, vitamin D $2.5 \mu$ g fortified egg, vitamin D $10 \mu \mathrm{g}$ fortified egg and a mixture of ordinary egg and authentic vitamin $D$. These samples were orally administered and vitamin $D$ intakes of these groups were approximately $0.03,0.19,0.77$ and $0.77 \mu$ ger day per rat. In comparison with the ordinary egg group, the vitamin D $10 \mu$ g fortified egg group was significantly higher in femur weight, femur length, tibia length, humerus length and ulna length. From histological photomicrographs of the rat's lumbar vertebrae, the average width of mineralized trabecular bone in the vitamin $D 10$ rg fortified egg group was larger than that in the ordinary egg group, and active osteoid formation was observed in the former group. Comparing bone parameters between the groups supplemented with the same amount of vitamin $D$ either as egg or as authentic compound, they were significantly higher or slightly higher in the former than in the latter. These results indicated that sufficient amounts of vitamin D supplementation from egg were effective for bone growth even in ovariectomized rats.
\end{abstract}

Keywords: vitamin D, egg, osteoporosis, bone strength

Recently, osteoporosis has been widely recognized as a public health problem because Japan has been rapidly becoming an elderly society. Osteoporosis is one of the involutional disorders with bone loss and fracture. The number of patients with bone fractures due to osteoporosis is increasing.

It is well known that the common type of osteoporosis is the post-menopausal bone loss associated with ovarian hormone deficiency (Melton et al, 1988). Therefore, the ovariectomized osteoporosis model rat (Ezawa et al., 1981; Omi \& Ezawa, 1993) has been successfully used as an experimental animal for the study of osteoporosis. Vitamin $\mathrm{K}_{2}$ (Akiyama et al., 1993) and ipriflavone (Tsutsumi et al., 1994) were examined using this experimental animal as part of the development of medicines for osteoporosis, these substances can prevent bone loss by ovariectomy. Also, food materials such as globin (Omi et al, 1992a), spiny lobster shell (Omi et al, 1992b), soybean milk (Omi et al, 1994) and tochu bark (Jiu et al, 1994) were examined, which suggested that the effective component affecting bone metabolism exist in these foods. Furthermore, the effect of swimming and voluntary exercise were examined using this experimental animal (Morita et al., 1989). It was determined that moderate exercise was effective for the prevention of osteoporosis. As for the effect of vitamin $\mathrm{D}$ in ovariectomized osteoporotic rats, the active form of vitamin D such as $1 \alpha(\mathrm{OH}) \mathrm{D}_{3}$ (Higuchi et al. 1994), $1 \alpha, 25(\mathrm{OH})_{2} \mathrm{D}_{3}$ (Ezawa et al., 1984; Matsumoto et al., 1985), 2 $\beta$-(3-hydroxypropoxy)- $1 \alpha, 25(\mathrm{OH})_{2} \mathrm{D}_{3}$ [ED71] (Kobayashi et al., 1993) were investigated for the purpose of the medical treatment of osteoporosis. However, few papers have been published on the effect of vitamin D in food on bone metabolism using this experimental animal.

Today, it is considered that the medical treatment of osteoporosis is difficult. Consequently, the prevention of osteoporosis has become very important. Therefore, it is necessary to take enough calcium, and to also take vitamin D which regulates calcium metabolism for the prevention of osteoporosis. However, most foods contain little or no vitamin $\mathrm{D}$, except for fish and dried shiitake mushrooms (Lentinus edodes) which are abundant in vitamin D (Takeuchi et al., 1993a). So, vitamin D-fortified egg can be expected as a good source of vitamin D in daily diets.

In this experiment, vitamin D-fortified egg containing various amounts of vitamin $\mathrm{D}$ were used and the effect of vitamin $\mathrm{D}$ in these eggs on bone metabolism was examined using ovariectomized osteoporotic rats.

\section{Materials and Methods}

Materials Ordinary egg, vitamin D-fortified egg containing about $2.5 \mu \mathrm{g}$ of vitamin D per egg and vitamin $\mathrm{D}$-fortified egg containing about $10 \mu \mathrm{g}$ of vitamin D per egg were used. These eggs were obtained from laying hens fed a basal diet containing the vitamin $\mathrm{D}_{2}$-fortified shiitake (vita$\min \mathrm{D}_{2}$ content was $4,000 \mathrm{IU} / \mathrm{g}$ ) at the levels of $0,0.2$ and $0.8 \%$ (Kawazoe et al, 1994). After the eggs were broken, the egg yolks were carefully separated and freezed-dried. Contents of vitamin $\mathrm{D}$ and $25(\mathrm{OH}) \mathrm{D}$ in these freezed-dried egg yolks are shown in Table 1. The determinations of vitamin $\mathrm{D}$ and $25(\mathrm{OH}) \mathrm{D}$ in these egg yolks were carried out by HPLC (Takeuchi et al, 1984). The contents of protein, fat and ash in these egg yolks were almost the same (data not shown). Commercially available authentic vitamin $\mathrm{D}_{2}$ was purchased from Wako Pure Chem. Ind., Ltd (Osaka).

Experimental animals and feeding protocol Twentyeight 5-week-old Sprague-Dawley female rats were ovariectomized and fed on a low calcium diet for 30 days to 
Table 1. Contents of vitamin $\mathrm{D}$ and $25(\mathrm{OH}) \mathrm{D}$ in dried egg yolks.

\begin{tabular}{|c|c|c|c|c|}
\hline & $\begin{array}{c}\text { Vitamin } D_{2} \\
(\mu \mathrm{g} / \mathrm{g})\end{array}$ & $\begin{array}{c}\text { Vitamin } \mathrm{D}_{3} \\
(\mu \mathrm{g} / \mathrm{g})\end{array}$ & $\begin{array}{c}25(\mathrm{OH}) \mathrm{D}_{2} \\
(\mu \mathrm{g} / \mathrm{g})\end{array}$ & $\begin{array}{c}25(\mathrm{OH}) \mathrm{D}_{3} \\
\quad(\mu \mathrm{g} / \mathrm{g})\end{array}$ \\
\hline Ordinary egg & N.D. & 0.042 & N.D. & 0.011 \\
\hline Vitamin D $2.5 \mu \mathrm{g} \mathrm{egg}^{(a)}$ & 0.236 & 0.033 & 0.017 & 0.009 \\
\hline Vitamin D $10 \mu \mathrm{g} \mathrm{egg}^{b}$ & 1.056 & 0.028 & 0.072 & 0.008 \\
\hline
\end{tabular}

Means of two determinations. N.D.: not detected $(<5 \mathrm{ng} / \mathrm{g})$.

a) Vitamin D $2.5 \mu \mathrm{g}$ egg: vitamin D-fortified egg containing about $2.5 \mu \mathrm{g}$ of vitamin D per egg.

b) Vitamin D $10 \mu \mathrm{g}$ egg: vitamin D-fortified egg containing about $10 \mu \mathrm{g}$ of vitamin D per egg.

Table 2. Composition of low calcium and experimental diets.

\begin{tabular}{|c|c|c|}
\hline Component & $\begin{array}{l}\text { Low calcium diet } \\
\text { (weight \%) }\end{array}$ & $\begin{array}{c}\text { Experimental diet } \\
\text { (weight \%) }\end{array}$ \\
\hline Glucose monohydrate & 65.1 & 64.6 \\
\hline Casein (Vitamin free) & 18.0 & 18.0 \\
\hline Cottonseed oil & 10.0 & 10.0 \\
\hline Roughage & 3.0 & 3.0 \\
\hline $\mathrm{Ca}-$ and P-free salt mixture ${ }^{a)}$ & 2.0 & 2.0 \\
\hline $\begin{array}{l}\text { Mixture of } \mathrm{KH}_{2} \mathrm{PO}_{4} \\
\text { and } \mathrm{K}_{2} \mathrm{HPO}_{4}(1: 1, \mathrm{w} / \mathrm{w})\end{array}$ & 1.39 & 1.39 \\
\hline $\mathrm{CaCO}_{3}$ & 0.005 & 0.5 \\
\hline Cystine & 0.2 & 0.2 \\
\hline Choline chloride & 0.2 & 0.2 \\
\hline Water-soluble vitamin mixture ${ }^{b)}$ & 0.1 & 0.1 \\
\hline \multicolumn{3}{|l|}{ Fat-soluble vitamin mixture ${ }^{c)}$} \\
\hline \multicolumn{3}{|c|}{$\begin{array}{l}\text { a) } \mathrm{Ca} \text { - and P-free salt mixture: } \mathrm{KCl}, 57.7 \% ; \mathrm{NaCl}, 20.9 \% ; \mathrm{MgSO}_{4}, 17.9 \% \text {; } \\
\mathrm{FeSO}_{4} \cdot 7 \mathrm{H}_{2} \mathrm{O}, 3.22 \% ; \mathrm{CuSO}_{4} \cdot 5 \mathrm{H}_{2} \mathrm{O}, 0.078 \% ; \mathrm{NaF}, 0.113 \% ; \mathrm{CoCl}_{2} \cdot 6 \mathrm{H}_{2} \mathrm{O} \text {, } \\
0.004 \% ; \mathrm{KI}, 0.01 \% ; \mathrm{MnSO}_{4} \cdot 5 \mathrm{H}_{2} \mathrm{O}, 0.06 \% ; \mathrm{ZnSO}_{4} \cdot 7 \mathrm{H}_{2} \mathrm{O}, 0.44 \% \text { and }\left(\mathrm{NH}_{4}\right) \\
6 \mathrm{Mo}_{7} \mathrm{O}_{24} \cdot 4 \mathrm{H}_{2} \mathrm{O}, 0.005 \% \text {. } \\
\text { b) } \mathrm{The} \text { water-soluble vitamin mixture: thiamine, } 0.5 \% \text {; riboflavin, } 0.5 \% \text {; pyridox- } \\
\text { ine, } 0.5 \% \text {; calcium pantothenate, } 2.8 \% \text {; nicotinamide, } 20 \% ; m \text {-inositol, } 20.0 \% \text {; } \\
\text { folic acid, } 0.02 \% \text {; vitamin } \mathrm{B}_{12}, 0.002 \% ; \text { biotin, } 0.01 \% \text { and glucose monohydrate, } \\
73.7 \% \text {. } \\
\text { c) The rats received a supplement of the following fat-soluble vitamins in } \\
\text { cottonseed oil three times a week: } \beta \text {-carotene, } 70 \mu \mathrm{g} ; 2 \text {-methyl-1,4- } \\
\text { naphthoquinone, } 105 \mu \mathrm{g} \text { and } \alpha \text {-tocopherol, } 875 \mu \mathrm{g} \text {. }\end{array}$} \\
\hline
\end{tabular}

produce experimental osteoporosis (Ezawa et al, 1981; Omi \& Ezawa, 1993). The composition of the low calcium diet is shown in Table 2. The low calcium diet contained $0.01 \%$ calcium and $0.3 \%$ phosphorus. Vitamin $\mathrm{D}_{2}$ was received at the level of $0.5 \mu \mathrm{g}$ per day per rat with oral administration during the period of the low calcium diet. Thereafter, the rats were divided into four groups of seven rats each: the ordinary egg group, the vitamin D $2.5 \mu \mathrm{g}$ fortified egg group, the vitamin D $10 \mu \mathrm{g}$ fortified egg group and the mixture of ordinary egg and authentic vitamin $\mathrm{D}_{2}$ group. The rats in each group were fed the experimental diet as shown in Table 1 for the next 28 days. The experimental diet contained $0.2 \%$ calcium, $0.3 \%$ phosphorus but did not contain vitamin $\mathrm{D}$. As a vitamin $\mathrm{D}$ source, the rats in each group received $0.714 \mathrm{~g}$ of the egg yolks containing different amounts of vitamin D. Each egg yolk was suspended in $1 \mathrm{ml}$ of $5 \%$ Tween 80 solution and they were orally administered once a day for 28 days. The rats in the mixture of ordinary egg and authentic vitamin $\mathrm{D}_{2}$ group received both $0.714 \mathrm{~g}$ of ordinary egg yolk and $0.744 \mu \mathrm{g}$ of authentic vitamin $D_{2}$. The vitamin $D$ intake in each group is summarized in Table 3. The vitamin $\mathrm{D}$ intake of the mixture of ordinary egg and authentic vitamin $\mathrm{D}_{2}$ group was about equal to that of the vitamin D $10 \mu \mathrm{g}$ fortified egg group. During the periods of a low calcium diet and the experimental diet, all the rats were kept in separate cages and allowed free access to the diet and ion-exchanged distilled water. The conditions in the animal laboratory were as follows: the temperature was kept at $23 \pm 1^{\circ} \mathrm{C}$, the humidity was maintained at $50 \pm 5 \%$ and the fluorescent lighting was on from $7: 00$ a.m. to $7: 00$ p.m.

Biochemical assays of serum At the end of this experiment, all the rats were deprived of food for one night ( $7: 00$ p.m. $-9: 00$ a.m.). The next day, after anesthetizing with ether, blood samples were taken from the abdominal aorta. The blood samples were centrifuged at 2,500 r.p.m. for $15 \mathrm{~min}$. Serum samples were separated and frozen at $-20^{\circ} \mathrm{C}$ and then stored until analysis. The level of serum calcium was measured by the orthocresolphthalein complexone method (Connery \& Briggs, 1966) using commercial kits (705CA) from Eiken Chemical Co., Ltd. (Tokyo). Phosphorus was measured by the direct method of molybdic acid (Daly \& Ertingshausen, 1972) using commercial kits (Muki Rin-HA

Table 3. Experimental groups and vitamin $D$ intake in each group.

\begin{tabular}{|c|c|c|c|c|}
\hline & $\begin{array}{l}\text { Amount of egg } \\
\text { yolk given } \\
\text { (g/day/rat) }\end{array}$ & $\begin{array}{c}\text { Amount of authentic } \\
\text { vitamin } D_{2} \text { given } \\
(\mu \mathrm{g} / \text { day } / \text { rat })\end{array}$ & $\begin{array}{c}\text { Amount of vitamin } \mathrm{D} \\
\text { by administration } \\
(\mu \mathrm{g} / \text { day } / \mathrm{rat})\end{array}$ & $\begin{array}{c}\text { Vitamin D biological } \\
\text { activitye) } \\
\text { (IU/day/rat) }\end{array}$ \\
\hline Ordinary egg ${ }^{a)}$ & 0.714 & - & 0.03 & 2.78 \\
\hline Vitamin D $2.5 \mu \mathrm{g} \mathrm{egg}^{b)}$ & 0.714 & - & 0.19 & 11.34 \\
\hline Vitamin D $10 \mu \mathrm{gegg}^{c)}$ & 0.714 & - & 0.77 & 42.38 \\
\hline Mixture of egg and vitamin $\mathrm{D}^{d)}$ & 0.714 & 0.744 & 0.77 & 33.74 \\
\hline
\end{tabular}

${ }^{a)}$ Administration of dried egg yolk of ordinary egg containing $0.5 \mu \mathrm{g}$ vitamin D per egg.

b) Administration of dried egg yolk of fortified egg containing $2.5 \mu \mathrm{g}$ vitamin D per egg.

c) Administration of dried egg yolk of fortified egg containing $10 \mu \mathrm{g}$ vitamin D per egg.

(c) Administration of mixture of dried ordinary egg yolk and authentic vitamin $\mathrm{D}_{2}$.

e) The biological activity of vitamin D was calculated by means of the coefficient of Reeve et al. (Reeve et al. 1982) using the values vitamin D and 25(OH)D except $1 \alpha, 25(\mathrm{OH})_{2} \mathrm{D}$. (The biological activity of $25(\mathrm{OH}) \mathrm{D}$ is 5 fold of that of vitamin D.) 
Test Wako) from Wako Pure Chem. Ind., Ltd. Serum total cholesterol was measured by enzymatic procedures using commercial kits (Cholesterol-HR) from Wako Pure Chem. Ind., Ltd. The alkaline phosphatase activity was determined by the $p$-nitrophosphate method (Van Belle, 1976) using commercial kits (Arukarisei phospha II-HA) from Wako Pure Chem. Ind., Ltd. Serum calcitonin was determined by radioimmunoassay using commercial kits (Karushitonin RIA Mitsubishi) from Mitsubishi Chemical Co., Ltd. (Tokyo) (Takami et al, 1989). The concentrations of $25(\mathrm{OH})$ $\mathrm{D}_{2}$ and $25(\mathrm{OH}) \mathrm{D}_{3}$ in serum were determined by HPLC (Okano et al, 1981).

Measurements of wet weight and length of bone During dissection, the femur, tibia, scapula, humerus, ulna, radius and the second lumbar vertebra were isolated. The muscles and connective tissues were carefully removed and the wet weight of these bones were measured. The length of these bones were measured by slide calipers.

Measurement of mechanical strength and mineral contents in femur The mechanical strength of the femoral bone was determined by the breaking test using an instrument (Iio Co., Tokyo, type DYN-1255) according to the method of Ezawa et al. (Ezawa et al, 1979). In this study, the breaking force and breaking energy were measured. Afterwards, all femurs were lyophilized and the dry weight was measured. Thereafter, lyophilized femurs were incinerated at $550-600^{\circ} \mathrm{C}$ for $24 \mathrm{~h}$ and the femoral ash weight measured. These were then dissolved into $1 \mathrm{~N}$ nitric acid and the contents of calcium and phosphorus in the femur were measured using atomic absorption spectrometry.

Histological examination The 3rd lumbar vertebraes of ordinary egg and vitamin D $10 \mu \mathrm{g}$ fortified egg groups were fixed with $10 \%$ formaldehyde solution. The undecalcified bone samples were dehydrated in ethanol and embedded in methylmethacrylate. Thereafter, the blocks were cut into thin sections. The samples were stained with villanueva goldner stain (Villanueva, 1983) and observed using an optical microscope.

Statistical methods Data were expressed as the mean \pm SD. The statistical significance of differences from the ordinary egg group were calculated according to a one-way analysis of variance by Dunnett's test for multiple group comparison.

\section{Results and Discussion}

Food intake and body weight The food intake and the body weight are shown in Fig. 1. The food intake was almost the same in all groups, and the body weight increased under normal conditions during the experimental period.

The biochemical data of serum The biochemical data of serum is shown in Table 4. These values of serum calcium and phosphorus were within the normal range. Also these values showed no differences among the four groups. Calcitonin and alkaline phosphatase activity were almost the same in all groups. The level of serum total cholesterol in all groups were slightly higher than the normal range because egg yolk was rich in cholesterol. The concentration of 25(OH)D in serum increased with the supplementation of vitamin $\mathrm{D}$ from the egg yolk among the ordinary egg, vitamin D $2.5 \mu \mathrm{g}$ fortified egg and vitamin D $10 \mu \mathrm{g}$ fortified egg groups. However, between the groups supplemented with the same amount of vitamin D either as egg yolk or as authentic compound, the $25(\mathrm{OH}) \mathrm{D}$ concentration in serum was the same level. These results indicated that vitamin D in egg yolk was absorbed into the rat's body and metabolized to $25(\mathrm{OH}) \mathrm{D}$ in the liver, and also vitamin $\mathrm{D}$ in egg yolk was equal to authentic vitamin $\mathrm{D}_{2}$ absorption in the rat's body.

Bone analysis Wet weight and bone length are shown in Table 5. For the femur weight, femur length, tibia length, humerus length and ulna length, these values of the vitamin $\mathrm{D} 10 \mu \mathrm{g}$ fortified egg group were significantly higher than that of the ordinary egg group. On the whole, the wet weight and bone length in the vitamin D $10 \mu \mathrm{g}$ fortified egg group tended to be higher than that in the ordinary egg group.
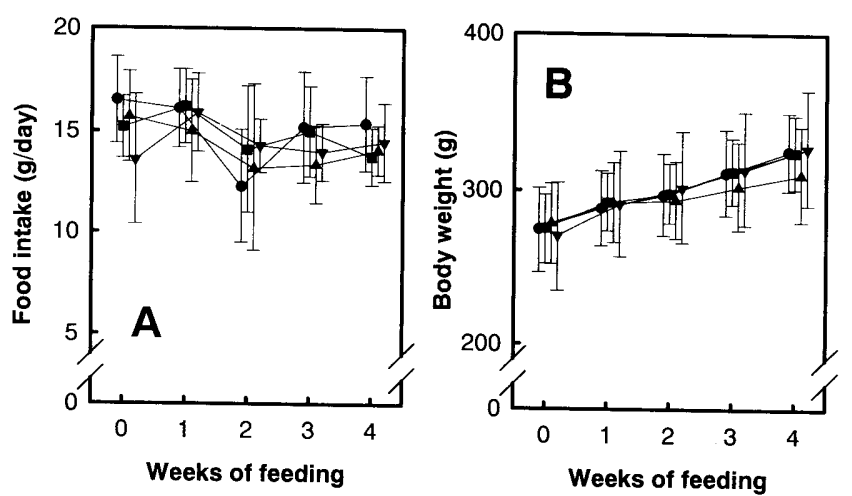

Fig. 1. Weekly variation in food intake (A) and body weight (B) of ovariectomized osteoporotic rats in each group. Mean $\pm \mathrm{SD}(n=7)$. o ordinary egg, $\mathbf{v i t a m i n}$ D $2.5 \mu \mathrm{g}$ fortified egg, $\boldsymbol{\Delta}$ vitamin D $10 \mu \mathrm{g}$ fortified egg, $\boldsymbol{\nabla}$ mixture of ordinary egg and authentic vitamin $D_{2}$.

Table 4. Biochemical data of serum at the end of the experiment.

\begin{tabular}{|c|c|c|c|c|}
\hline & Ordinary egg & $\begin{array}{l}\text { Vitamin D } \\
2.5 \mu \mathrm{g} \mathrm{egg}\end{array}$ & $\begin{array}{l}\text { Vitamin D } \\
10 \mu \mathrm{g} \mathrm{egg} \\
\end{array}$ & $\begin{array}{l}\text { Mixture of egg } \\
\text { and vitamin D }\end{array}$ \\
\hline Calcium $(\mathrm{mg} / 100 \mathrm{ml})$ & $9.95 \pm 0.42$ & $10.2 \pm 0.4$ & $9.96 \pm 0.23$ & $10.2 \pm 0.2$ \\
\hline Phosphorus $(\mathrm{mg} / 100 \mathrm{ml})$ & $5.47 \pm 0.86$ & $5.79 \pm 0.39$ & $5.20 \pm 0.79$ & $5.36 \pm 0.93$ \\
\hline Calcitonin (pg/ml) & $71.0 \pm 47.4$ & $78.7 \pm 41.2$ & $60.2 \pm 23.5$ & $57.6 \pm 15.9$ \\
\hline Alkaline phosphatase activity (IU $/ l$ ) & $369 \pm 127$ & $281 \pm 81$ & $301 \pm 93$ & $343 \pm 71$ \\
\hline Total cholesterol $(\mathrm{mg} / 100 \mathrm{ml})$ & $111 \pm 6$ & $99 \pm 17$ & $112 \pm 17$ & $111 \pm 13$ \\
\hline $25(\mathrm{OH}) \mathrm{D}(\mathrm{ng} / \mathrm{ml})^{a}$ & $2.5 \pm 0.5$ & $6.5 \pm 1.5$ & $11.8 \pm 2.8$ & $12.5 \pm 2.4$ \\
\hline
\end{tabular}

a) Determination of $25(\mathrm{OH}) \mathrm{D}$ is total of $25(\mathrm{OH}) \mathrm{D}_{2}$ and $25(\mathrm{OH}) \mathrm{D}_{3}$. 
Table 5. Wet weight and length of bones.

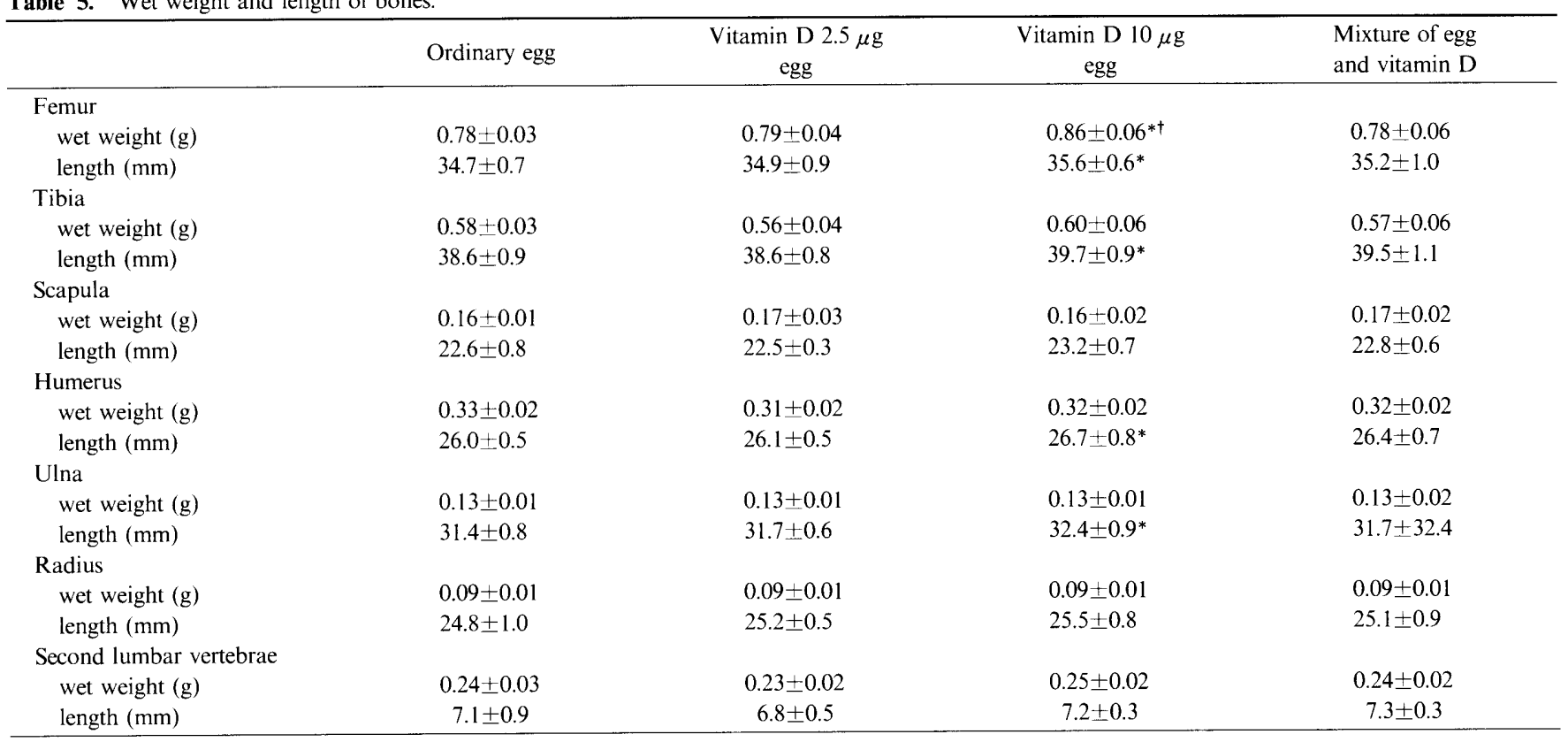

Mean $\pm \operatorname{SD}(n=7)$.

* Significantly different from the ordinary egg group, $p<0.05$.

† Significantly different between Vitamin D $10 \mu \mathrm{g}$ egg group and ordinary egg and vitamin D group, $p<0.05$.

Table 6. Dry weight, ash and mineral contents of femur.

\begin{tabular}{lccc}
\hline & Ordinary egg & $\begin{array}{c}\text { Vitamin D 2.5 } \mu \mathrm{g} \\
\text { egg }\end{array}$ & $\begin{array}{c}\text { Vitamin D 10 } \mu \mathrm{g} \\
\text { egg }\end{array}$ \\
\hline Dry weight (g/piece) & $0.53 \pm 0.04$ & $0.54 \pm 0.04$ & $0.57 \pm 0.06$ \\
Ash (\% dry weight) & $48.8 \pm 1.2$ & $49.4 \pm 1.5$ & $50.2 \pm 2.2$ \\
Calcium (\% dry weight) & $18.9 \pm 0.4$ & $19.0 \pm 0.5$ & $19.1 \pm 0.4$ \\
Phosphorus (\% dry weight) & $8.36 \pm 0.16$ & $8.49 \pm 0.27$ & $8.63 \pm 0.29^{*}$ \\
\hline
\end{tabular}

Mean \pm SD $(n=7)$.

* Significantly different from the ordinary egg group, $p<0.05$.
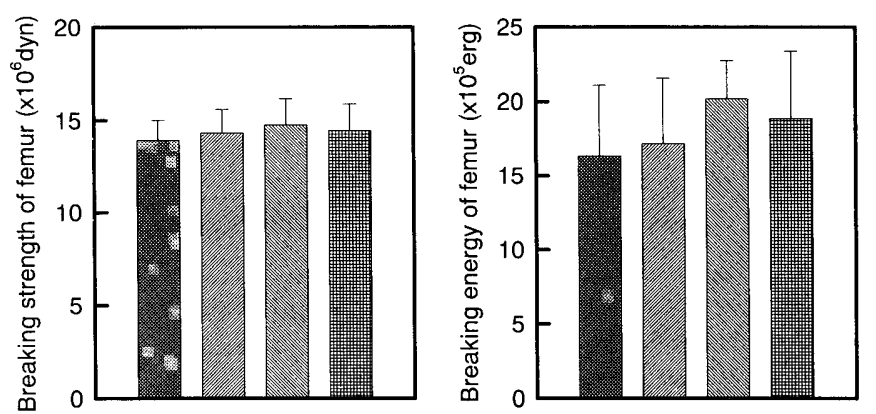

Fig. 2. Femoral mechanical bone strength (breaking force (A) and breaking energy (B)) of ovariectomized osteoporotic rats. Mean $\pm \mathrm{SD}(n=7)$. 0 ordinary egg, vitamin D $2.5 \mu \mathrm{g}$ fortified egg, vitamin D $10 \mu \mathrm{g}$ fortified egg, mixture of ordinary egg and authentic vitamin $D_{2}$.

The mechanical strength of the femur is shown in Fig. 2. The breaking force and the breaking energy were the highest in the vitamin D $10 \mu \mathrm{g}$ fortified egg group followed by the vitamin D $2.5 \mu \mathrm{g}$ fortified egg group, and lowest in the ordinary egg group among the three groups. The mechanical strength tended to be higher with increasing supplement of vitamin $\mathrm{D}$ from the egg yolk. However, there was no significant differences. As shown in Table 6, the phosphorus content in the femur of the vitamin D $10 \mu \mathrm{g}$ fortified egg group was significantly higher than that of the ordinary egg group, however, there were no significant differences in the femoral dry weight, femoral ash and calcium content in femur.

The effect of vitamin D on the bone of rat had been formerly investigated by the line test method. The line test was the method of vitamin D assay such that the degree of calcification was evaluated at the distal end of the radius or ulna using rachitogenic rats. Increased supplementation of vitamin $\mathrm{D}$ from $0.05 \mu \mathrm{g}$ to $0.3 \mu \mathrm{g}$ provided increased calcification of bone in rachitogenic rats (Moriuchi, 1983). Also, vitamin D-deficient rats were used in the study of vitamin $\mathrm{D}$ and bone. It was reported that the bone of this experimental animal with supplementation of sufficient vitamin $\mathrm{D}(0.25 \mu \mathrm{g} / \mathrm{day} / \mathrm{rat})$ was strong in comparison with the supplementation of a low vitamin $\mathrm{D}(0.0025 \mu \mathrm{g} / \mathrm{day} / \mathrm{rat})$ for the values of mechanical strength, density and mineral contents (Okano et al., 1992, 1993).

On the other hand, it was considered that ovariectomized 
osteoporotic model rats were produced under mild conditions in comparison with rachitogenic rats or vitamin D-deficient rats, because the concentrations of calcium and phosphorus in serum were maintained in the normal range. In this experiment, the administration amount of vitamin D from eggs was set at $0.03,0.19$ and $0.77 \mu \mathrm{g}$ per day per rat, which was around the vitamin D required amount of rats ( $0.25 \mu \mathrm{g}$ per day). The calcium content in the experimental diet was set at a relatively low level $(0.2 \%)$. This is the reason why the calcium intake of the Japanese is about $500 \mathrm{mg}$ per person per day and has never been sufficient.

Despite the differences in administrations of vitamin $\mathrm{D}$, the increases in body weight, food intake and the biochemical data of serum (calcium, phosphorus, calcitonin and alkaline phosphatase activity) were almost the same in all groups. However, as far as femur weight, femur length, tibia length, humerus length and ulna length are concerned, these values of the vitamin D $10 \mu \mathrm{g}$ fortified egg group were significantly
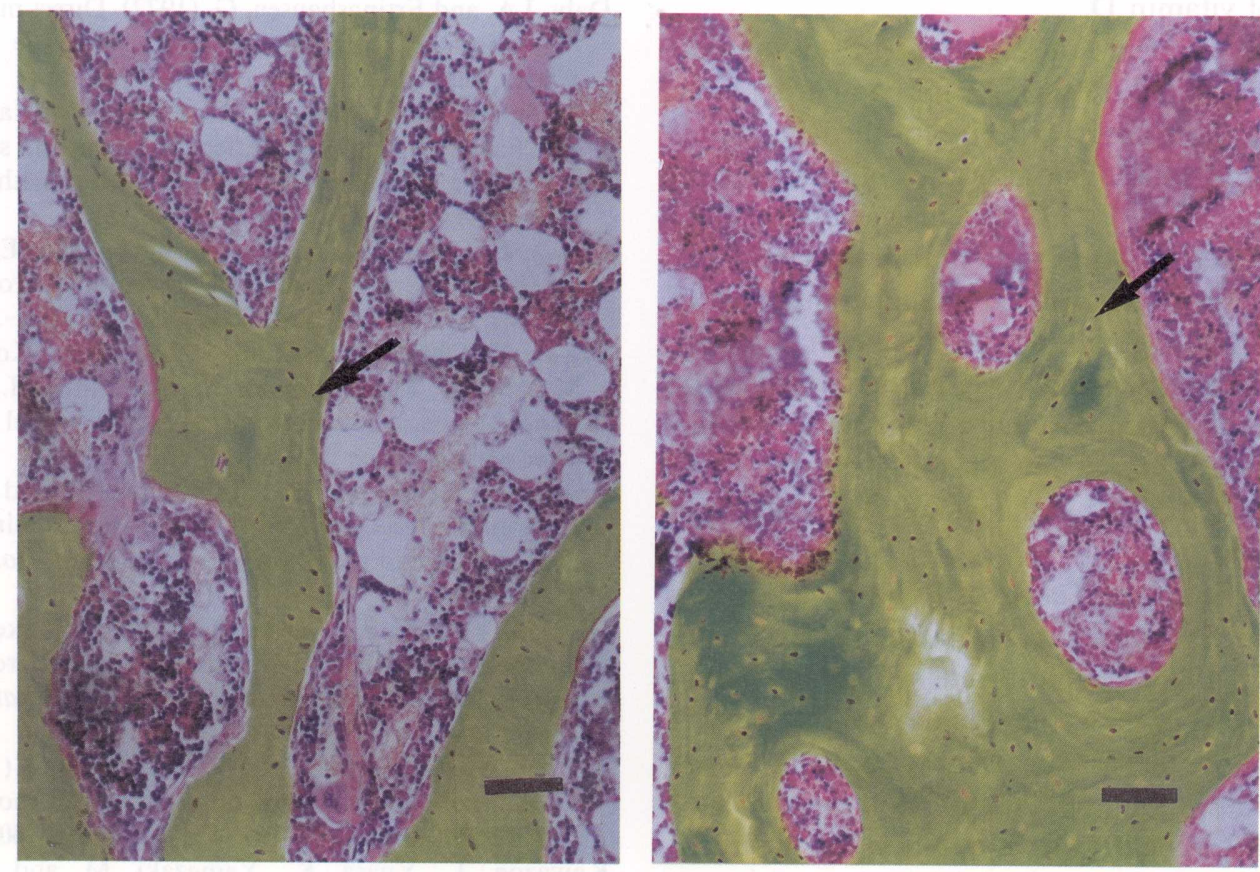

Fig. 3. Histological photomicrograph of mineralized trabecular bone (arrow, yellowish-green) from rat's 3rd lumbar vertebrae in ordinary egg and fortified egg containing $10 \mu \mathrm{g}$ vitamin D per egg groups. Bar: $200 \mu \mathrm{m}$.
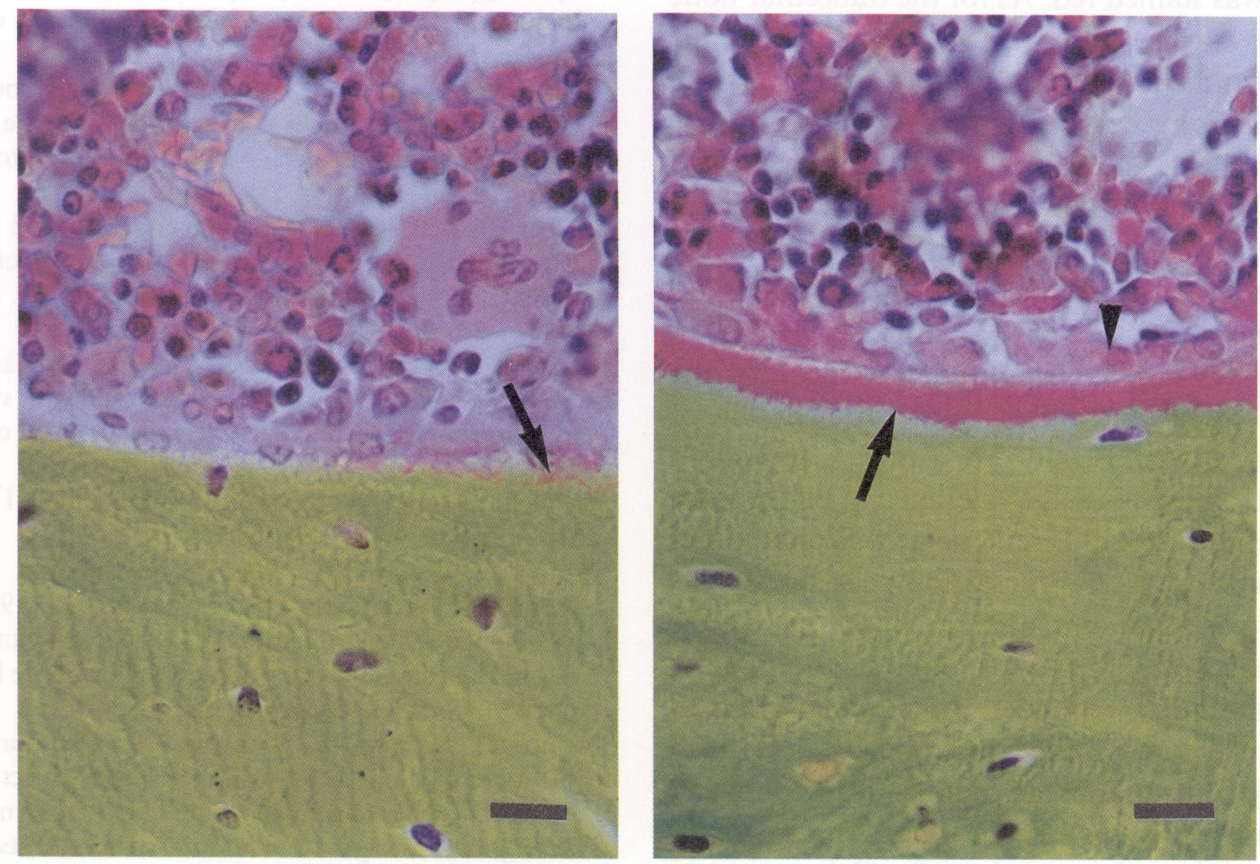

Fig. 4. Histological photomicrograph of osteoid seam (arrow, red) on mineralized trabecular bone (yellowish-green). Active fromation of osteoid by osteoblast (४) was observed in rat's 3rd lumbar vertebrae of fortified egg containing $10 \mu \mathrm{g}$ vitamin D groups. Bar: $50 \mu \mathrm{m}$. 
higher than that of the ordinary egg group. The phosphorus content in the femur of the vitamin D $10 \mu \mathrm{g}$ fortified egg group was significantly higher than that of the ordinary egg group. These results suggested that sufficient amounts of vitamin D supplementation were effective for bone growth even in ovariectomized rats.

It was reported that healthy postmenopausal women with a vitamin D intake of $10 \mu \mathrm{g}$ per day for over one year can significantly increase the net bone density of the spine (Dawson-Hughes, 1991). Vitamin D-fortified eggs can be a good source of vitamin $\mathrm{D}$ for the sake of the positive supplementation of vitamin D.

Eggs contain low contents of $25(\mathrm{OH}) \mathrm{D}$ in addition to vitamin D (Takeuchi et al., 1993b). As for comparing bone parameters between the vitamin D $10 \mu \mathrm{g}$ fortified egg group and the mixture of ordinary egg and authentic vitamin $\mathrm{D}$ group, the nutritional effect of $25(\mathrm{OH}) \mathrm{D}$ in egg yolk on bone was examined. The wet weight of the femur in the vitamin D $10 \mu \mathrm{g}$ fortified egg group was significantly higher than that of the mixture of ordinary egg and authentic vitamin D group. Also, the vitamin D $10 \mu \mathrm{g}$ fortified egg group tended to be higher than the mixture of ordinary egg and authentic vitamin $\mathrm{D}$ group in the breaking force and breaking energy. These results indicated that $25(\mathrm{OH}) \mathrm{D}$ in the vitamin D-fortified egg also affected the bone.

According to the Standard Tables of Food Composition in Japan-Vitamin D-(Resources Council Science and Technology Agency, 1993), the biological activity of vitamin $\mathrm{D}$ in egg was described as the values including both vitamin $\mathrm{D}$ and $25(\mathrm{OH}) \mathrm{D}$. As far as egg was concerned, it was considered that the metabolites of vitamin $\mathrm{D}$ in egg were also effective nutrients for bone growth in addition to vitamin D.

Histological photomicrograph Histological photomicrographs of the third lumbar vertebrae are shown in Fig. 3 and Fig. 4. Using villanueva goldner stain, the trabecular bone of a calcificated section was stained a yellowish green color and osteoid was stained red. As for the trabecular bone (Fig. 3), the narrow trabecular was well observed in the lumbar vertebrae from the ordinary egg group and a wide trabecular was well observed in the lumbar vertebrae from the vitamin D $10 \mu \mathrm{g}$ fortified egg group. As for the observation of osteoid on the surface of the trabecular bone (Fig. 4), osteoid was hardly observed in the ordinary egg group. However, the formation of osteoids was observed in the vitamin D $10 \mu \mathrm{g}$ fortified egg group.

Bone is continuously regenerated throughout life. First, the osteoclasts resorb trabecular bone. Next, an osteoid or unmineralized bone matrix is laid down on the trabecular bone surface by osteoblasts. Finally, calcium and phosphorus were deposited and the osteoid is mineralized. Formation of a strong trabecular network and increasing peak bone mass during the growth period of animals were important for the prevention of osteoporosis. In the histological photomicrographs of the rat's lumbar vertebrae, the average width of mineralized trabecular bone in the vitamin D $10 \mu \mathrm{g}$ fortified egg group was larger than that in the ordinary egg group, and active osteoid formation was observed in the former group. This suggested that the supplementation of sufficient vitamin $\mathrm{D}$ was related to the positive formation of trabecular bone.
Acknowledgments The authors thank Dr. Naomi Omi for measuring the mechanical strength of the femoral bone, and also thank Dr. Ikuko Ezawa for the valuable suggestion and discussion. The authors also thank Showa Sangyo Co., Ltd. for supplying the vitamin D-fortified eggs containing various amounts of vitamin $\mathrm{D}$ for our experiment.

\section{References}

Akiyama, Y., Hara, K., Ohkawa, I. and Tajima, T. (1993). Effects of menatetrenone on bone loss induced by ovariectomy in rats. Jpn. J. Pharmacol., 62, 145-153.

Connery, H.V. and Briggs, A.R. (1966). Determination of serum calcium by means of orthocresolphthalein complexone. Am. J. Clin. Pathol., 45, 290-296.

Daly, J.A. and Ertingshausen, G. (1972). Direct method for determining inorganic phosphate in serum with the cantrifichem. Clin. Chem., 18, 263-265.

Dawson-Hughes, B., Dallal, G.E., Krall, E.A., Harris, S., Sokoll, L.J. and Falconer, G. (1991). Effect of vitamin D supplementation on wintertime and overall bone loss in healthy postmenopausal women. Ann. Intern. Med., 115, 505-512.

Ezawa, I., Okada, R., Nozaki, Y. and Ogata, E. (1979). Breakingproperties and ash contents of the femur of growing rat fed a low calcium diet. J. Jpn. Soc. Food Nutr., 32, 329-335.

Ezawa, Y., Ohnuma, N., Hino, S., Sagara, K., Koyama, T., Kikkoji, M., Makita, T., Hashimoto, Y. and Orimo, H. (1981). Studies on bone disorder in ovariectomized rats. A model of postmenopausal osteoporosis. Bone Metab., 14, 271-279.

Ezawa, I., Kawanobe, Y., Matsumoto, T. and Ogata, E. (1984). Favorable effects of $1,25(\mathrm{OH})_{2} \mathrm{D}_{3}$ in vivo on mineral metabolism of ovariectomized rats fed on a low Ca diet. J. Bone Mineral Metab., 2, 107-113.

Higuchi, Y., Sato, K., Nanjo, M., Isogai, T., Takeda, S., Kumaki, K. and Nishii, Y. (1994). $1 \alpha$-hydroxycholecalciferol prevents osteoporosis induced by ovariectomy in the rats. Vitamins, 68, 87-93 (in Japanese).

Jiu, L.J., Morikawa, N., Omi, N. and Ezawa, I. (1994). The effect of tochu bark on bone metabolism in the rat model with ovariectomized osteoporosis. J. Nutr. Sci. Vitaminol., 40, 261-273.

Kawazoe, T., Yuasa, K., Yamazaki, M. and Ando, M. (1994). Production of vitamin D-fortified egg by feeding the vitamin $\mathrm{D}_{2}$-fortified shiitake. J. Jpn. Soc. Food Sci. Technol., 41, 891-897.

Kobayashi, T., Okano, T., Tsugawa, N., Murano, M., Masuda, S.,

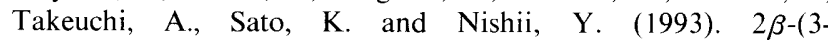
hydroxypropoxy)-1 $\alpha, 25$-dihydroxy-vitamin $\mathrm{D}_{3}$ (ED-71) preventive and therapeutic effects on bone mineral loss in ovariectomized rats. Bioorg. Med. Chem. Lett., 3, 1815-1819.

Matsumoto, T., Ezawa, I., Morita, K., Kawanobe, Y. and Ogata, E. (1985). Effect of vitamin D metabolites on bone metabolism in a rat model of postmenopausal osteoporosis. J. Nutr. Sci. Vitaminol., 31 (Suppl.), S61-S65.

Melton III, L.J., Kan, H.S., Wahner, W.H. and Riggs, B.L. (1988). Lifetime fracture risk; an approach to hip fracture risk assessment based on bone mineral density and age. J. Clin. Epidemiol., 41, 985994.

Morita, K., Futami, Y., Suzuki, Y., Nagasawa, S. and Ezawa, I. (1989). Favorable effect of voluntary exercise and swimming on bone metabolism of a rat model of postmenopausal osteoporosis. J. Jpn. Soc. Nutr. Food Sci., 40, 765-768.

Moriuchi, S. (1983). "Bitamingaku Jikkenho [I]." Tokyo Kagaku Dojin Inc., p. 132 (in Japanese).

Okano, T., Mizuno, N., Shida, S., Takahashi, N., Kobayashi, T., Kuroda, E., Kodama, S. and Matsuo, T. (1981). A method for simultaneous determination of 25-hydroxyvitamin $D_{2}$ in human plasma by using two steps of high-performance liquid chromatography. J. Nutr. Sci. Vitaminol., 27, 43-54.

Okano, T., Kimura, T., Tsugawa, N., Okamura, Y., Ooshio, Y., Teraoka, Y. and Kobayashi, T. (1992). Effect of dietary calcium intake and supplement of vitamin $\mathrm{D}_{3}$ on bone mineral contents, density and strength in vitamin D-deficient rats. Vitamins (Japan), 66, 457-468 (in Japanese).

Okano, T., Kimura, T., Tsugawa, N., Okamura, Y., Fujiwara, M. 
Yamamoto, M. and Kobayashi, T. (1993). Effect of dietary calcium intake on bone mineral content and strength in marginally vitamin D-deficient rats. Vitamins, 67, 331-338 (in Japanese).

Omi, N., Morikawa, N., Hoshina, A. and Ezawa, I. (1992a). The effect of globin powder on bone mineral density in model rats with postmenopausal osteoporosis. J. Jpn. Soc. Nutr. Food Sci, 45, 271276.

Omi, N., Morikawa, N. and Ezawa, I. (1992b). The effect of spiny lobster shell powder on bone metabolism in ovariectomized osteoporotic model rats. J. Nutr. Sci. Vitaminol., 38, 555-563.

Omi, N. and Ezawa, I. (1993). Techniques for inducing osteoporosis in animals. Igaku no Ayumi, 165, 577-580 (in Japanese).

Omi, N., Aoi, S., Murata, K. and Ezawa, I. (1994). Evaluation of the effect of soybean milk and soybean kilk peptide on bone metabolism in the rat model with ovariectomized osteoporosis. J. Nutr. Sci. Vitaminol., 40, 201-211.

Reeve, L.E., Jorgensen, N.A. and Deluca, H.F. (1982). Vitamin D compounds in cows milk. J. Nutr., 112, 667-672.

Resources Council Science and Technology Agency (1993). Japan Standard Tables of Food Composition in Japan-Vitamin D- (in Japanese).

Takami, H., Shikata, J. and Ito, K. (1989). Basic and clinical studies on calcitonin kit "Mitsubishi Yuka." Horumon to Rinsho, 37, 151-155 (in Japanese).

Takeuchi, A., Okano, T., Teraoka, S., Murakami, Y. and Kobayashi, T. (1984). High-performance liquid chromatographic determination of vitamin D in foods, feeds and pharmaceuticals by successive use of reversed-phase and straight-phase columns. J. Nutr. Sci. Vitaminol., 30, 11-25.

Takeuchi, A., Okano, T. and Kobayashi, T. (1993a). Determination of vitamin $\mathrm{D}$ and provitamin $\mathrm{D}$ in various kinds of Japanese foods. Vitamins, 67, 321-330 (in Japanese).

Takeuchi, A., Okano, T., Hirahara, F. and Kobayashi, T. (1993b). Dietary intake of vitamin D in nomal Japanese. Vitamins, 67, 417427 (in Japanese).

Tsutsumi, N., Kawashima, K., Nagata, H., Tsuyuki, J., Itoh, F., Arai, H., Kojima, M., Ujie, A. and Endo, H. (1994). Effects of KCA-098 on bone metabolism: comparison with those of ipriflavone. Jpn. J. Pharmacol., 65, 343-349.

Van Belle, H. (1976). Alkaline phosphatase, kinetics and inhibition by levamisole of purified isoenzymes from humans. Clin. Chem., 22, 972-976.

Villanueva, A.R. (1983). Preparation and staining of mineralized section of bone. In "Handbook of Bone Morphometry," ed. by T Takahashi. Nishimura Shoten, Niigata, pp. 45-55. 